\title{
BASE ISOLATION OF TIMBER-FRAMED BUILDINGS
}

\author{
Stuart J. Thurston ${ }^{1}$
}

\begin{abstract}
SUMMARY
This paper investigates the practicality of using base-isolation devices to protect lightweight buildings, such as timber-framed houses, against earthquakes.

As the timber-framed buildings considered are designed to a lateral seismic force of $0.24 \mathrm{~W}$ in Wellington (where $\mathrm{W}$ is building weight), it was considered that the appropriate isolation level should be significantly lower, say $0.1 \mathrm{~W}$, and lower still in Auckland where such buildings are designed for a lateral force of $0.12 \mathrm{~W}$. An analysis showed that houses which had a base-isolation yield set to yield at $0.1 \mathrm{~W}$ would have unacceptable deformations under the design wind load if the isolators were located beneath a timber floor, but may be satisfactory if located beneath a concrete slab. A large-scale test using isolators beneath pre-cast floor slabs showed the method used would work even if it was unduly expensive. However, an analysis indicated that there might be little protection for some building contents.

A literature survey of alternative base-isolation solutions showed a wide range of innovative, but often impractical, concepts have been proposed. However, one concept showed promise for timber-framed structures. This used two layers of synthetic sheet beneath a concrete floor slab to provide a slip layer. The sheet materials recommended reputably gave a dynamic friction coefficient of 0.07. BRANZ measured the friction coefficient using large samples of both these and other sheet materials. It was concluded that the measured friction was too high for use for the planned buildings, although it may have application for low-rise heavy-brittle construction.
\end{abstract}

Alternative base-isolation concepts are presented which will be useful to others interested in this topic.

\section{PERFORMANCE OF BASE ISOLATORS}

The seismic isolation considered in this study consists of inserting base-isolation devices (B.I.D.s) into a structure so that its fundamental period is significantly increased and energy is absorbed within the devices. The intent is to reduce building accelerations and thereby reduce damage to the building and its contents. The downside is the large displacements (usually 200+ mm) which are expected across the isolators in a design earthquake.

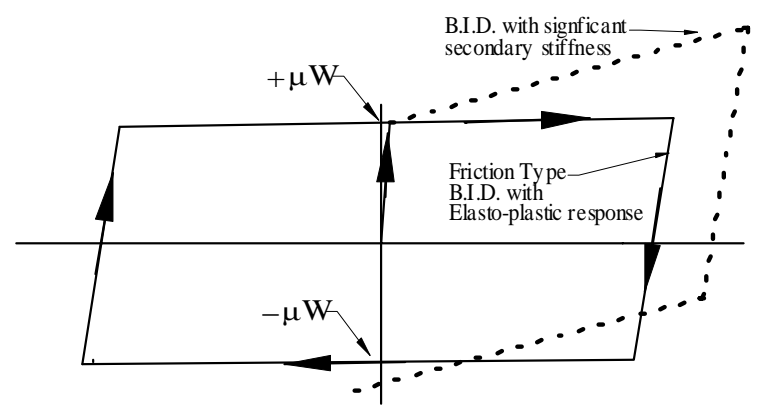

Figure 1. Hysteresis loops for the assumed B.I.D.s.

Initially this project was only concerned with the use of Roball $^{\mathrm{TM}}$ and Roglider ${ }^{\mathrm{TM}}$ B.I.D.s, as described by Robinson et al [1,2], and had the aim of investigating the practicality of application to small lightweight buildings like houses. This scope was subsequently broadened. When cycled, these classes of device give elasto-plastic hysteresis loops with a yield level of $\mathrm{W}$ as shown in Figure 1, where $\mathrm{W}$ is the axial load on the device and the friction coefficient, $\quad 0.08$ for the Roball and 0.11 for the Roglider. If the Roglider has a rubber membrane, as shown in Figure 2, the B.I.D. will have a significant secondary stiffness as plotted in Figure 1.

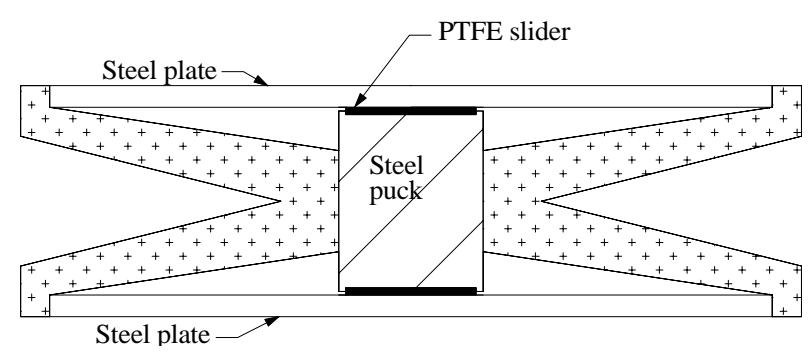

Figure 2. Section of full-size double-acting Roglider.

\section{LOCATION OF ISOLATORS}

Isolators can theoretically be used at any level in a building, e.g. below roofs or under walls as well as below ground floor level. As the isolators may deflect $200+\mathrm{mm}$ in a design earthquake there must be a diaphragm above and below them to force compatible displacements at each isolator, or otherwise the building will tear itself apart. Often the ground itself acts as the diaphragm below the isolators.

Many research papers propose using base isolators beneath masonry walls as illustrated in Figure 3. Thurston [3] provides examples. It can be seen that P- effects may cause problems if slip is large, and the wall flexural strength may be exceeded, unless the wall is very thick. Thurston [3] provides calculations to illustrate this.

Because of the problems detailed above, isolators in this project were only considered beneath ground floor level. A generalised sketch of such construction is illustrated in Figure

\footnotetext{
${ }^{1}$ Senior Structural Engineer, BRANZ Ltd, Judgeford, New Zealand (Member).
} 
4. Seismic gaps are required at the building edges to cater for the $200+$ mm design seismic movement across the isolators as shown. The design must ensure that the gaps remain operational for the life of the building and do not get filled with debris or water, or harbour rodents or insect pests.

If the 'stops' sketched in Figure 4 do not bring the building gently to rest large impact forces can be induced in the building. Further, once the house has reached the 'stop' the full earthquake force must be resisted by the house. 'Stops' have not been used in the systems recommended herein.

The construction cost of the system sketched in Figure 4 would be expensive with the upper slab probably needing to be made from pre-cast concrete for build-ability reasons. Access for inspection and maintenance is deemed to be inadequate for the construction in Figure 4. The minimum ground clearance for crawl space below timber floor joists is specified in NZS 3604 as $450 \mathrm{~mm}$.

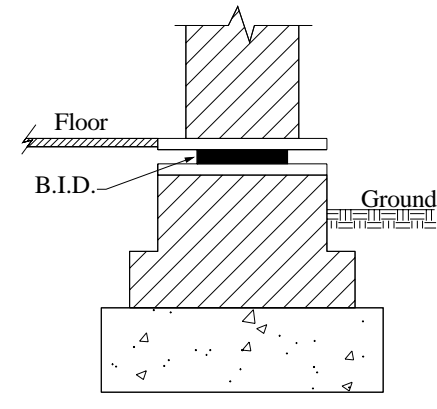

Example 1. China.

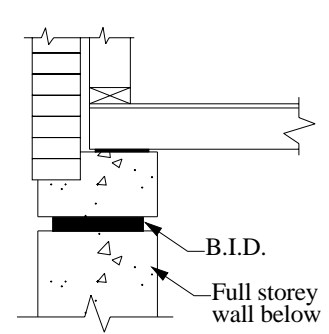

Example 2. Canada
Figure 3. Use of isolators under masonry walls.

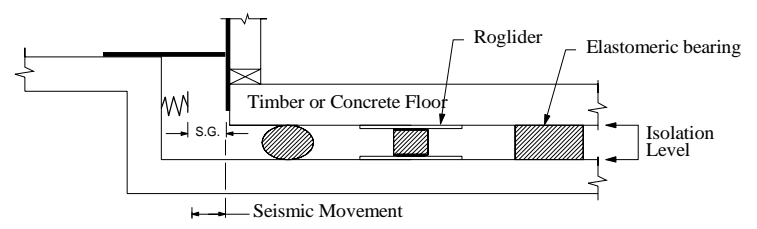

(a) At rest

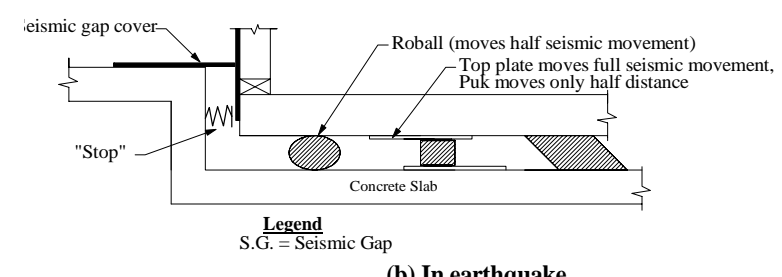

(b) In earthquake

Figure 4. Example of seismic movement in a base-isolated building.

\section{ISOLATORS BENEATH TIMBER FLOORS}

Thurston [3] proposed placing isolators on blocks of concrete and using Rogliders or Roballs on top as shown in Figure 5. A steel or timber plate beneath a pair of bearers would provide the bearing surface for the isolators. Thurston also proposed isolation details for use between timber piles and bearers and at concrete perimeter walls. However, the considerations for wind loading, discussed below, resulted in these ideas not being pursued.

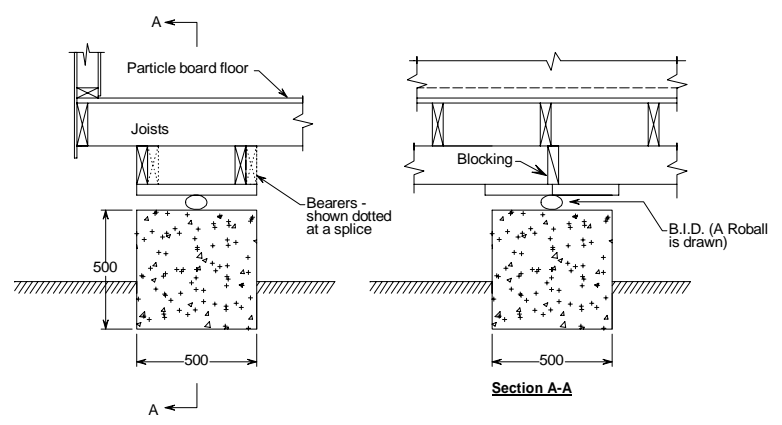

Figure 5. Proposed base-isolation system below a timber floor.

\section{WIND LOADING}

If yielding of B.I.D.s occurs under the '3-second' gust design wind speed the house may displace excessively and either strike the 'stop' (if one exists) or exceed the B.I.D. deflection limit. If the house strikes the 'stop' an impact force will be imparted to the house which is likely to cause damage.

To make an approximate estimate of the likely movement if the wind force exceeds the base-isolator yield force, BIYF, let us assume a house of weight, $\mathrm{W}$, and BIYF $=0.1 \mathrm{~W}$ subjected to a ' 3 second' gust wind force $10 \%$ higher than the BIYF (i.e. $0.11 \mathrm{~W}$ ). The house will therefore accelerate at $0.01 \mathrm{~g}$ for 3 seconds which (using the well-known formula $\mathrm{s}=$ ut + $0.5 \mathrm{at}^{2}$ ) will cause the house to displace a distance of $0.5 \times 0.01$ $\mathrm{x} 9.81 \times 3^{2}=0.44 \mathrm{~m}$. This is an excessive deflection. Hence, it is recommended that the minimum value of BIYF (which = $\mathrm{W}$ ) be set to 1.2 times the design wind strength $\left(\mathrm{F}_{\mathrm{w}}\right)$. Thus,

$$
\text { W } 1.2 \mathrm{~F}_{\mathrm{W}}
$$

To examine the relationship between the percentage of buildings suitable for isolation and the magnitude of the base slip coefficient, an analysis was performed using a BRANZ confidential database. This database lists details of individual house constructions throughout New Zealand, in a statistical sample of 2,954 houses constructed over the period 20042006. It is interesting to note that $91 \%$ of these houses were built on a concrete slab.

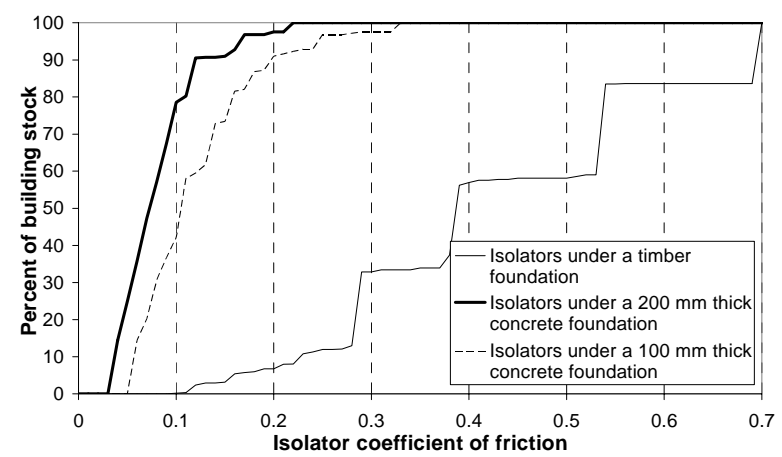

Figure 6. Percentage of buildings which may be isolated versus isolator coefficient of friction.

The analysis assumed all the houses were of rectangular plan dimensions $15 \mathrm{~m} \times 8 \mathrm{~m}$, and had a roof overhang of $0.6 \mathrm{~m}$. House weight and wind force were calculated for each house (defined in the database by location and construction description) and hence was calculated from Eqn (1). The results are shown in Figure 6. The plot for buildings constructed with isolators under a timber foundation is somewhat stepped, which is a reflection of the smaller number of houses on a timber foundation in the database (only 259) and also the stepwise nature of construction weights assumed. The plot shows that while very few houses with timber 
foundations will be suitable for isolation, many are suitable if founded on concrete slabs. However, use of B.I.D.s below concrete floor slabs is likely to require one of the following relatively expensive options:

(1) The floor is formed using pre-cast concrete slabs lowered onto the B.I.D.s, or

(2) The slab is cast on permanent formwork resting on the B.I.D.s.

\section{POTENTIAL PROBLEMS}

The potential for P- problems is illustrated in Figure 7, a) before the earthquake and $b$ ) after the earthquake. In the top diagram the movement of the B.I.D. (shown as a Roball) will result in a large flexural bending moment in the foundation slab. The bottom diagram considers the use of a B.I.D. between a pile top and bearer. This will result in instability if deflections are larger than shown or if the construction has inadequate strength to resist the P- bending moments.

Diaphragm stresses may sometimes need consideration, especially at the junction of different foundation types as illustrated in Figure 8. The two parts will need to be strongly tied together or else an adequate seismic gap needs to be provided both in the foundation and superstructure. Pile bracing must be adequate to resist the B.I.D. yield force.
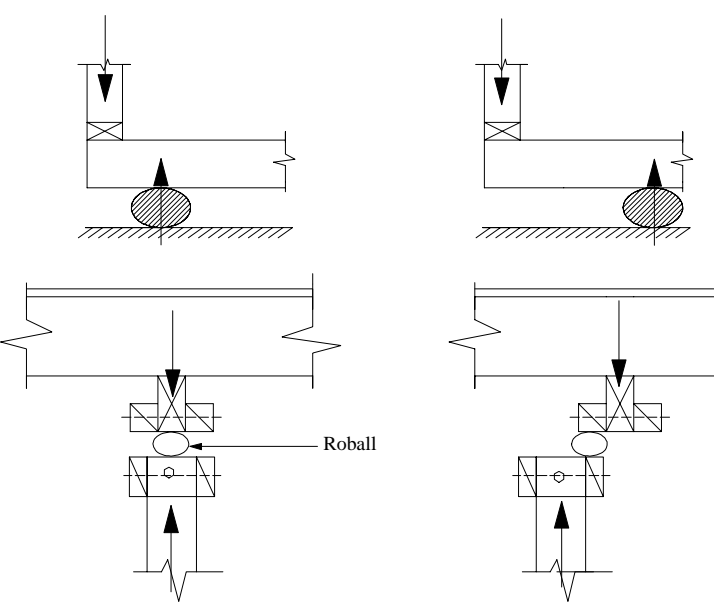

a) Before earthquake

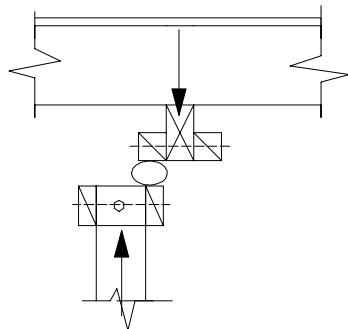

(b) After earthquake

Figure 7. Examples of 'P-Delta' problems in an earthquake in isolation construction.

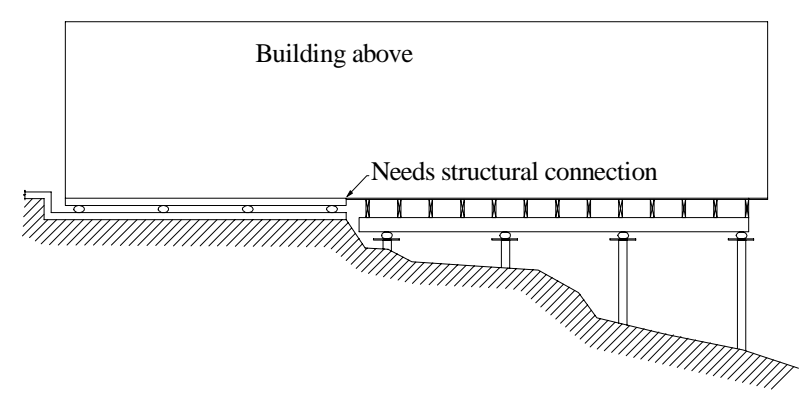

Figure 8. Schematic view of isolation of a mixed foundation system.

\section{BUILDING SERVICES}

Where the diaphragms above and below the B.I.D.s are well separated (e.g. by a storey height) the large design movements between the diaphragms can simply be provided for by coiling the services (e.g. water and sewerage pipes, electrical and communication cables) or by including flexible elements. However, where the gap is small (or there is none at all as in the case of a slip layer beneath a floor slab) a method to protect the services during earthquakes needs to be developed. A possible solution is to coil such services in a sump to the side of the building and allow them to enter the building above the slip layer.

\section{BENEFITS OF BASE ISOLATION}

It is sometimes difficult to provide adequate bracing in modern house construction due to the trend for large windows and sliding door openings and large room sizes. Thus, although the cost of bracing walls is relatively cheap, the extra expense of base isolation may not be justified. However, it is envisaged that the greatest scope is with specialised buildings where the cost of the contents is high or continued operation after an earthquake is imperative. Base isolation must be shown to protect these contents.

\section{PROTECTION OF HOUSE CONTENTS}

GNS Science (J Zhang personal communication 2004) provided floor response spectra for light buildings base isolated with devices having rectangular hysteresis loops as shown in Figure 1. A comparison of the ground motion response acceleration spectra with floor acceleration spectra for two assumed B.I.D. properties is given in Figure 9 for a major Wellington earthquake. If base isolation offers useful protection, then the floor spectra will be much lower than the ground spectra. However, it can be seen that for house contents with natural periods greater than one second no protection is provided. Contents that respond to shaking with a 'rocking body' behaviour, such as TVs, cabinets, bottles on shelves etc, fall into this category and often have 'effective' natural periods greater than one second. Thus, it is concluded that many of the contents of houses and similar buildings being considered for base isolation in this paper may receive little protection. As the response of 'rocking bodies' is complex, a more detailed analysis is required to confirm this finding. Many of the contents in commercial buildings are stiffer under lateral load and would thus receive protection from building isolation.

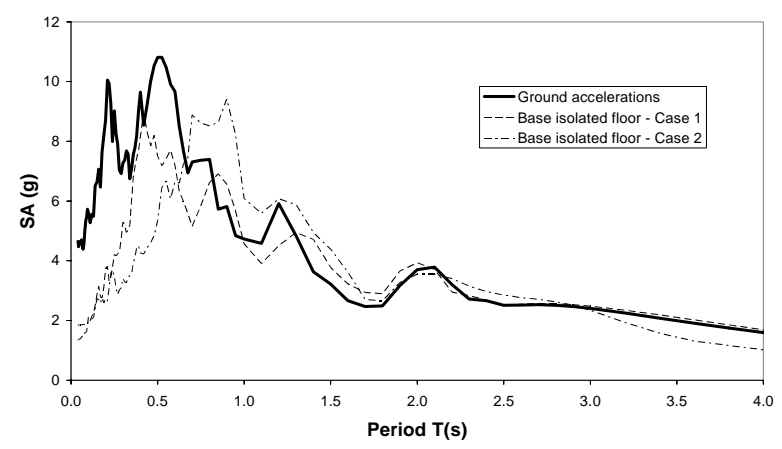

Figure 9. Comparison of acceleration spectra of raw earthquake signal and base-isolated floor.

\section{PROPOSAL FOR USE OF B.I.D.S BENEATH CONCRETE SLABS}

The writer proposes the system shown in Figure 10 and Figure 17 as a practical and perhaps the cheapest method of using B.I.D.s below a floor slab. A grid of pre-cast concrete blocks is levelled and dry-packed to bearing pads cast into the ground. A B.I.D. is fixed to the top of each block. Pre-cast 
beams are placed on the B.I.D.s and pre-cast slabs placed to span between these beams (without being directly connected as the slip coefficient is far higher than the isolator below). Finally, a concrete topping is poured.

This system was tested [3] as shown in Figure 18 and Figure 19 using simple low-load capacity, single-acting, Roglider B.I.D.s both with and without rubber membranes. Construction methods were developed to show such construction could be built by typical builders. Figure 19 shows bottles placed on top to investigate 'rocking body' response. Predicted slab motions from many major earthquakes were provided by GNS.

The slab was displaced to both sinusoidal and the GNS predicted motion up to $200 \mathrm{~mm}$ displacements and 250 $\mathrm{mm} / \mathrm{s}$ velocities. No damage occurred. However, the results showed that it was important that the rubber membrane was not too stiff otherwise large seismic forces were attracted which negated the purpose of the isolation.

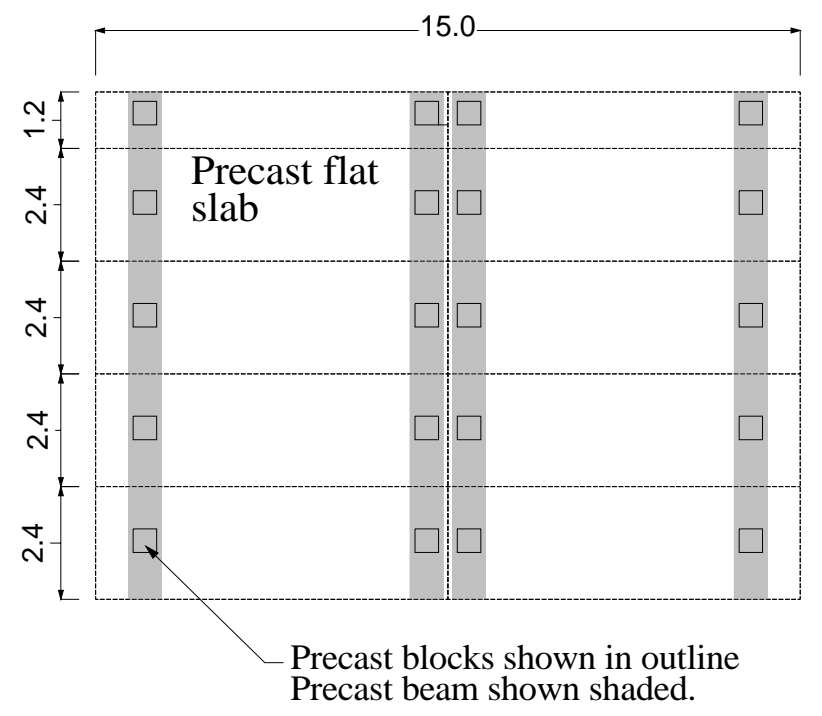

Figure 10. Plan layout of concrete block and slabs for proposed base-isolation scheme.

\section{LITERATURE REVIEW ON BASE ISOLATION OF LOW-RISE BUILDINGS USING SYNTHETIC LINERS}

Many authors have advocated using a slip layer beneath a building foundation to provide base isolation. Yegian and Kadakal [4] performed small-scale tests to measure the coefficient of friction, , at the interface of a variety of sheet materials using the set-up shown in Figure 11. They found the most suitable materials were Typar 3601 geo-textile placed over an ultra-high molecular weight polyethylene (UHMWPE). This gave static and dynamic coefficients of friction of 0.10 and 0.07 , respectively. However, the UHMWPE is expensive (BRANZ paid $\$ 106 / \mathrm{m}^{2}$ ).

By omitting the fixing to the rigid support the set-up shown in Figure 11 was modified to measure accelerations transmitted to the structure above. With simulated earthquake motions set to a maximum of $0.25 \mathrm{~g}$, the transmitted acceleration did not exceed 0.11g. Slip between table and weights reached $140 \mathrm{~mm}$.

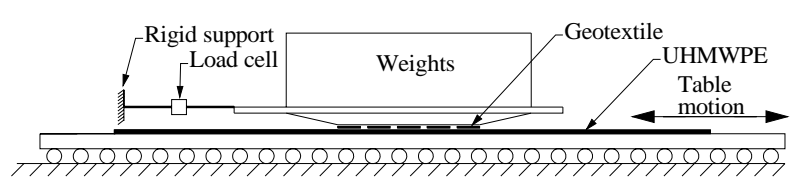

Figure 11. Yegian and Kadakal [4] tests.

Yegian and Catan [5] placed synthetic slip layers in a curved depression in soil within a box on a shake table as shown by a dark line in Figure 12. Soil was added to give a level surface as shown. In their shake table tests they found that the accelerations of the soil above the slip surface were significantly reduced near the centre of the 'bowl' but not so much near the edges.

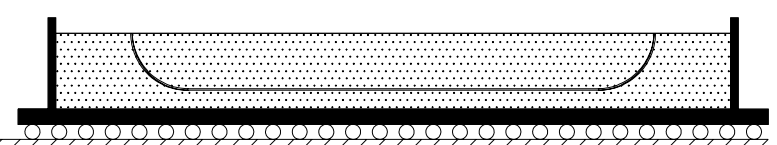

Figure 12. Yegian and Catan [5] shake table tests.

\section{PROPOSED CONSTRUCTION FOR NEW ZEALAND HOUSES USING SYNTHETIC LINERS}

The writer used the principles given by Yegian and Catan [5] to propose a base-isolation system for typical New Zealand houses as shown in Figure 13. The path slides on its own slip layer but need not extend around the entire building. Steps and other obstacles must be designed to slide. The depth of the edge footing allows for edge bearing and the design is not susceptible to water ingress. It is more likely to be practical in a sandy soil environment when foundation preparation is required anyway.

The writer also used the principles given by both Yegian and Kadakal [4] and Yegian and Catan [5] to propose a baseisolation system for standard houses (Figure 14). The slip layer is horizontal but soil is placed above the slip layer under most of the house. A sacrificial block is used to protect the edge slip layers adjacent to the building's external edges. A variation of this, but for a constant thickness foundation slab, is shown in Figure 15.

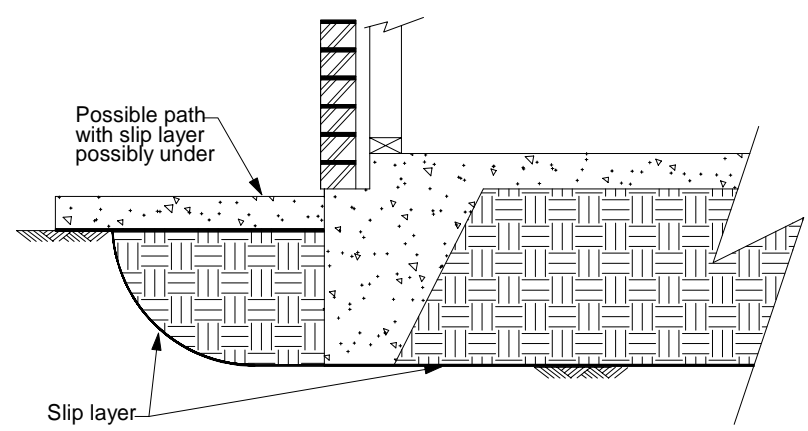

Figure 13. Variation of the system proposed by Yegian and Catan [6]. 


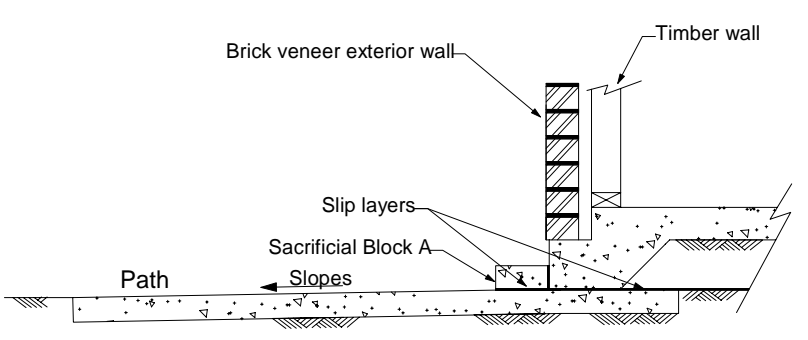

Figure 14. Variation of the systems proposed by Yegian and Kadakal [4] and Yegian and Catan [6].

Fibre cement cladding

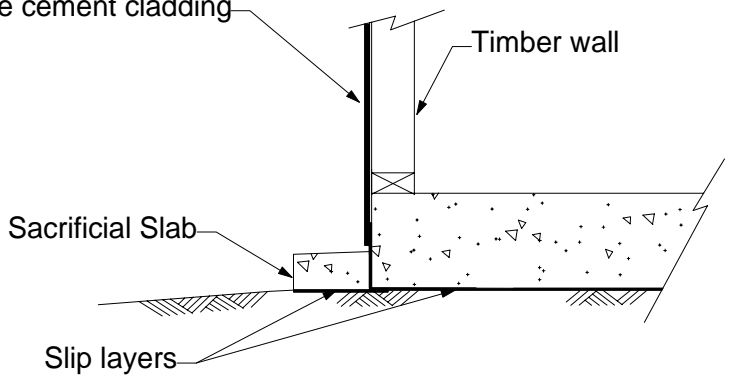

Figure 15. Variation of the system proposed by Yegian and Kadakal [4].

\section{BRANZ SLIP TESTS OF A CONCRETE SLAB SEATED ON SYNTHETIC LINERS}

Thurston [6] investigated the practicality of base-isolating low-rise buildings by placing synthetic liners beneath a $1.5 \mathrm{~m}$ long $\mathrm{x} 150 \mathrm{~mm}$ thick foundation slab. The authored determined the slip coefficients as a function of axial load, number of cycles and slab velocity for various liners using slip tests on the rig shown in Figure 16. This is a similar arrangement to that used by Yegian and Kadakal. The effect of grit on the surface, PTFE spray and grease and use of lap joints between sheets were examined.

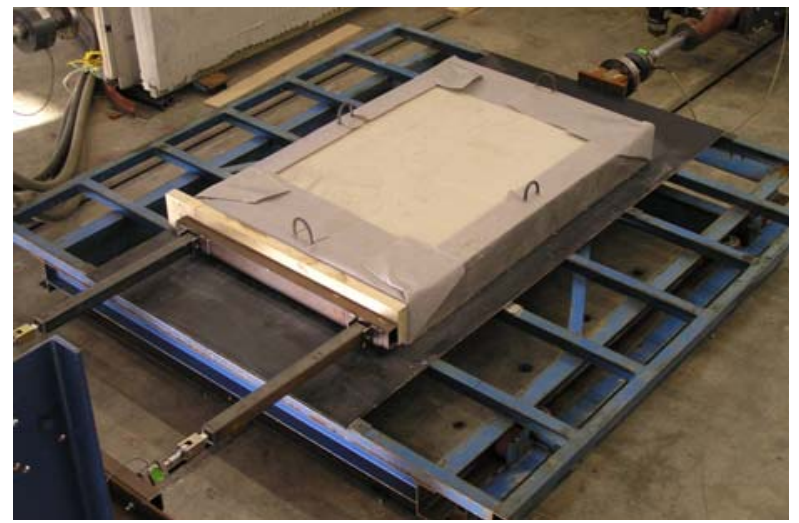

Figure 16. Set-up for slip tests using a shake table.

Thurston [3] found that the coefficient of friction, , for the interface of UHMWPE to Typar geo-textile was approximately 0.25 which was significantly greater than found by Yegian and Kadakal. This is possibly due to the moderately large scale of the tests completed by the above authors. Also, the Yegian and Kadakal tests were done with normal stresses greater than $40 \mathrm{kPa}$ and their plots showed decreased with increased axial load. Thurston's tests showed decreased from 0.25 to 0.21 when the axial stress increased from 3.9 to $10.9 \mathrm{kPa}$. When the surfaces were wet decreased to 0.16. In both Thurston's and Yegian and Kadakal's tests, was relatively constant with respect to velocity. The independence of to changes of temperature and possibly moisture is also important.

Although the concrete block was cast on the shaking table, subsequent measurements showed the under-surface to have a saucer-shaped profile, with the middle being approximately $1.5 \mathrm{~mm}$ lower than the end edges - possibly caused by drying. This may have increased measured values of . However, the bottom of the test specimen was flatter than can be relied upon in actual construction.

Tests showed that small sand particles at the interface increased the measured friction significantly. Hence it is expected that still higher values of than measured in Thurston's test would be present in field construction.

Typar-to-polypropylene and polythene-to-polypropylene interfacing surfaces both gave friction coefficients of 0.19 . Modifying these surfaces with PTFE spray reduced to 0.16 . The writer does not advocate such treatment until confidence in such modification remaining effective after a 50-year installation period is determined. The PTFE grease increased and is therefore not beneficial.

It was concluded that none of the examined products were suitable as a base-isolation system and the project was terminated.

\section{CONCLUSIONS AND DISCUSSION}

Implementing base isolation under low-rise timber-framed buildings may be justified where:

(1) There are insufficient bracing walls to meet demand; or

(2) Where protection of building contents is imperative.

It cannot be justified to reduce structural damage if there are sufficient walls which can be braced as the cost of bracing such walls is relatively low.

Where the diaphragms above and below an isolated level are well separated (e.g. by a storey height) the large design movements between the diaphragms can be simply provided for by coiling building services such as water pipes or by including flexible elements. However, where the gap is small (or none at all as in the case of a slip layer beneath a floor slab) a method to protect the services needs to be developed.

Unless isolators are located beneath heavy foundation slabs, excessive movement under design level wind speeds is likely. Buffers, stops or links which only fracture under earthquakes are options. Suitable designs for these devices were not considered in this paper.

Providing and maintaining a seismic gap around the building is likely to pose difficulties and may be expensive. A cover over a seismic gap is necessary for people safety.

The writer proposed a base-isolation system in which isolators were placed on concrete blocks and a suspended floor slab was located above. This avoided most of the problems listed above. A $5 \mathrm{~m} \times 2.4 \mathrm{~m}$ floor was constructed and tested at BRANZ to verify the build-ability and to check it functioned as designed. It proved to be successful but is likely to be too expensive for most situations.

A comparison of the floor acceleration spectra of light buildings isolated with B.I.D.s having rectangular hysteresis characteristics with the input ground acceleration spectra showed that there was negligible protection for contents with natural period greater than one second. Many house contents respond with a 'rocking action' and it would thus appear that 
isolation provides little protection to such house contents. Further analysis and tests are required to confirm this.

The writer has developed a practical method of base isolating timber-framed buildings using pre-cast concrete blocks and slabs using Rogliders or elastomeric bearings. This has potential for use in special buildings but is likely to be too expensive for typical houses.

A literature survey [3] found a wide range of innovative but often impractical base-isolation concepts have been proposed. However, one concept showed promise for timber-framed structures. This used a layer of UHMWPE and another of a specified geo-textile synthetic sheet beneath a concrete floor slab. This combination was stated to give a dynamic friction coefficient, , of 0.07 which was independent of axial load and velocity. However, the writer measured as 0.25 (which is a lot greater than 0.07) and found that the value was sensitive to surface grit and moisture. Material costs were high. A design where a slip layer was only required beneath edge thickening would reduce material costs significantly and perhaps allow Teflon sheet to be considered.

The use of a slip layer beneath concrete foundations has merit, and possible designs are proposed. However, suitable sheet materials for the system to be effective and yet economical have yet to be found.

\section{ACKNOWLEDGEMENTS}

This work was funded by the Foundation for Research, Science and Technology from the Public Good Science Fund under contract C05X0301.

\section{REFERENCES}

1 Robinson W.H., Gannon C.R. and Meyer J. (2006). “A Roball with an Elastic Restoring Force”. Bulletin of New Zealand Society of Earthquake Engineering 39 (1).

2 Robinson W.H., Gannon C.R. and Meyer J. (2006). “The RoGlider ${ }^{\mathrm{TM}}$ - A Sliding Bearing with an Elastic Restoring Force”. Bulletin of New Zealand Society of Earthquake Engineering 39 (1).

3 Thurston S.J. (2006). "Base Isolation of Low-Rise Light and Medium-Weight Buildings”. BRANZ Study Report SR 156. BRANZ Ltd, Judgeford, New Zealand. http://www.branz.co.nz/branzltd/publications/pdfs/SR156 .pdf.

4 Yegian M.K. and Kadakal U. (2004). "Foundation Isolation for Seismic Protection Using a Smooth Synthetic Liner". Journal of Geotechnical and Geoenvironmental Engineering 130 (11).

5 Yegian M.K. and Catan M. (2004). "Soil Isolation for Seismic Protection Using a Smooth Synthetic Liner". Journal of Geotechnical and Geoenvironmental Engineering ASCE (Nov): 1131.

6 Thurston S.J. (2007). "Base Isolation of Low-rise Buildings Using Synthetic Liners”. BRANZ Study Report SR 177. BRANZ Ltd, Judgeford, New Zealand. http://www.branz.co.nz/branzltd/publications/pdfs/SR177 .pdf. 


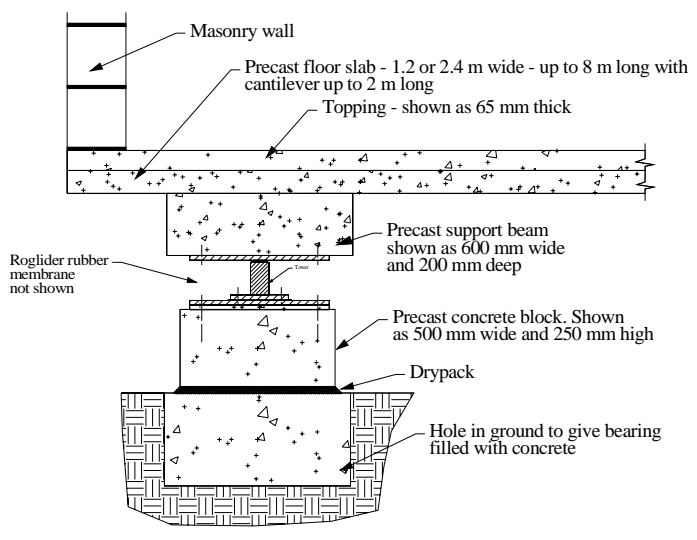

Along

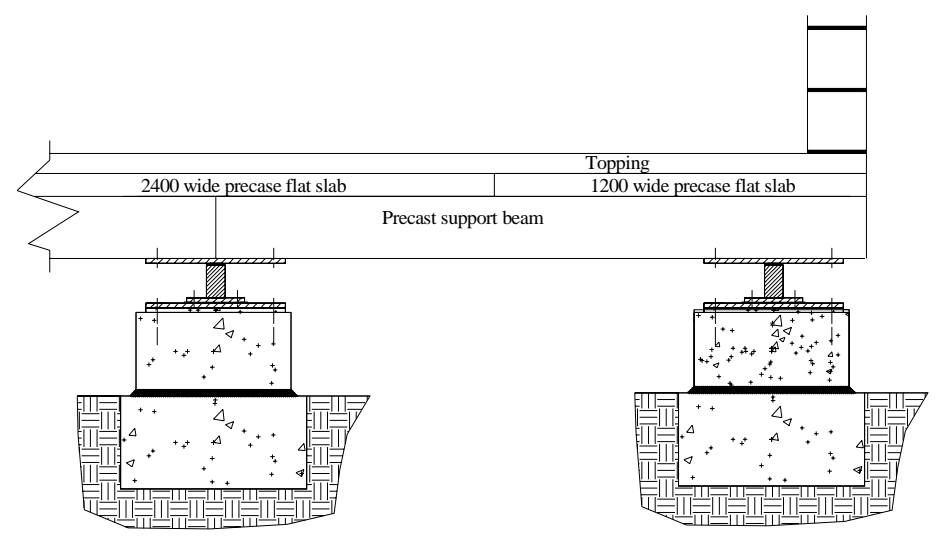

Across

Figure 17. Cross-section views of the foundation of a typical base-isolated house.

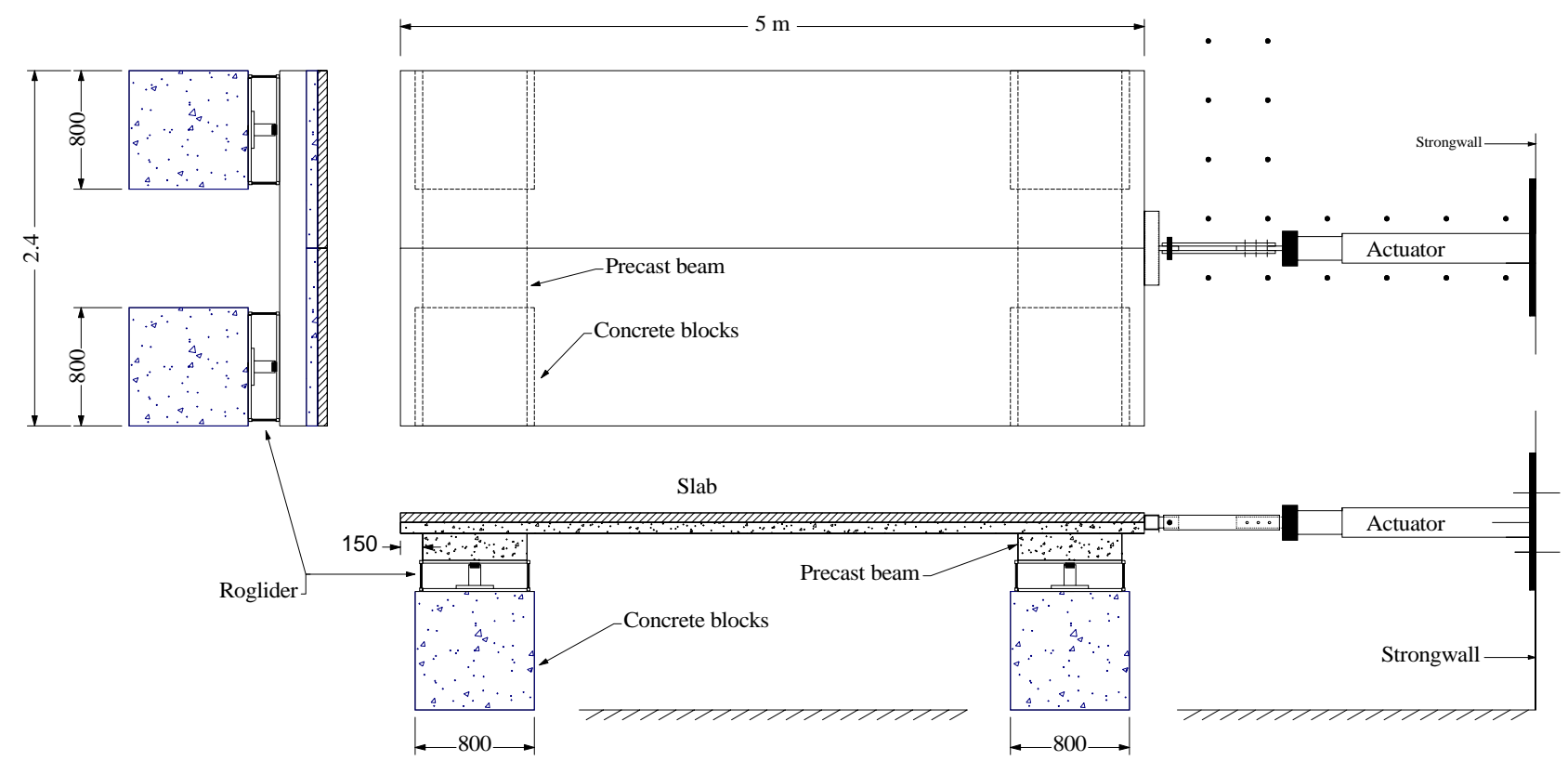

Figure 18. General views of test construction.

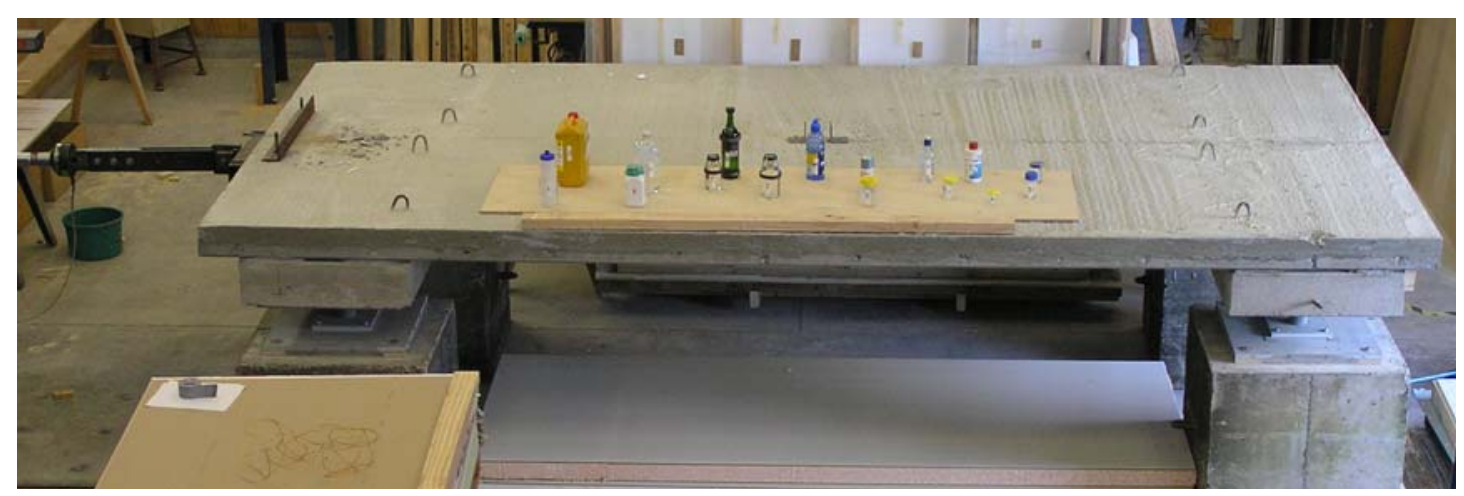

Figure 19. General photograph of test set-up. 